\title{
Intensification of Biological Wastewater Treatment Processes of the Food Complex Companies on the Basis of Hydro-Thermodynamic Cavitation
}

\author{
Olga G. Dubrovskaya, Vladimir A. Kulagin \\ Tatiana A. Kurilina and Anatoly I. Matyushenko* \\ Siberian Federal University \\ 79 Svobodny, Krasnoyarsk, 660041, Russia
}

Received 07.10.2017, received in revised form 26.02.2018, accepted 07.04.2018

The influence of biological contaminants of wastewater on the efficiency of aerotank operation with mixed aerobes location is studied. The effect of swelling and decontamination of sludge is discovered as a result of biocenosis oppression by biopollutants and their metabolic products neurotoxic poisons. The proposed intensification of the conditioning process flow and increasing the efficiency of biological treatment through the introduction of node cavitation treatment of waste water.

Keywords: waste water conditioning, biopollutant, cavitation effect, bioreactors, biofilters.

Citation: Dubrovskaya O.G., Kulagin V.A., Kurilina T.A. Intensification of biological wastewater treatment processes of the food complex companies on the basis of hydro-thermodynamic cavitation, J. Sib. Fed. Univ. Eng. technol., 2018, 11(5), 584-590. DOI: 10.17516/1999-494X-0057.

\section{Интенсификация процессов биологической очистки сточной воды предприятий пищевого комплекса на основе эффектов гидротермодинамической кавитации}

О.Г. Дубровская, В.А. Кулагин, Т.А. Курилина, А.И. Матюшенко Сибирский федеральный университет Россия, 660041, Красноярск, пр. Свободныий, 79

Исследовано влияние биологических примесей сточной воды на эффективность работь аэротенков со смешанным расположением аэробов. Обнаружен эффект вспухания $u$ дезактивации активного ила вследствие угнетения биоценоза биополлютантами и их

(C) Siberian Federal University. All rights reserved

* Corresponding author E-mail address: dubrovskayaolga@mail.ru 
Olga G. Dubrovskaya, Vladimir A. Kulagin... Intensification of Biological Wastewater Treatment Processes...

продуктами метаболизма - нейротоксическими ядами. Предложена интенсификация процесса кондиционирования стока и повышение эффективности биологической очистки за счет внедрения узла кавитационной обработки сточной воды.

Ключевые слова: кондиционирование сточныхвод, биополютанты, кавитационноевоздействие, биореакторы, биофильтры.

Сточные воды предприятий отрасли пищевой промышленности относятся к категории высококонцентрированных стоков по содержанию органических загрязнителей и биополлютантов.

В большом количестве в них содержатся органические загрязнения естественного происхождения. Кроме того, в сточные воды в значительных количествах поступают минеральные примеси и поверхностно-активные вещества. Минеральными загрязнениями этих стоков являются хлориды, нитраты, минеральные взвешенные вещества.

Основной задачей при решении вопроса модернизации локальных очистных установок для кондиционирования сточных вод предприятий пищевого комплекса выступает интенсификация процессов биологической очистки. Как известно, чаще всего для биологической очистки стока используют аппараты, в которых аэробный биологический агент находится в культуральной жидкости во взвешенном состоянии либо в иммобилизованном состоянии, т.е. прикреплен к поверхности твердого носителя. В технологических схемах локальных очистных установок наиболее распространены биофильтры или биотенки - аппараты смешанного расположения аэробов. Эффективность работы подобных сооружений зависит от ряда факторов, таких как интенсивность аэрации, время аэрирования, тип распределительной системы подачи воздуха, количественный и качественный состав сточной воды, следствием которого является нагрузка на активный ил и т.д. Работа биофильтра оценивается по глубине очистки от загрязнителей. Однако до сих пор не существует единого мнения о причинах снижения эффективности функционирования аэробной биосистемы фильтров, вспухания ила, потери способности к воспроизведению аэробов, остановки работы биофильтров.

Стремление интенсифицировать процессы биологической очистки, как правило, приводит к созданию новых конструкций биореакторов, в которых аэрация производится техническим кислородом. Данное техническое решение оправдано высокой скоростью и эффективностью очистки.

В условиях реального функционирования предприятия с точки зрения техникоэкономических показателей замена имеющегося биофильтра чаще всего невозможна, следовательно, нужно выявить конкретные причины снижения эффективности работы установки биологической очистки и выбрать способ улучшения ее работы.

Лабораторией кафедры инженерных систем зданий и сооружений Инженерностроительного института Сибирского федерального университета определен качественный и количественный состав биологических загрязнителей стока предприятия молочной переработки. Биологические загрязнения представляют собой различные микроорганизмы: дрожжевые и плесневые грибки, мелкие водоросли и бактерии, в том числе болезнетворные.

Данные микроорганизмы способны оказывать вред как экологической среде и человеку, так и инженерным сооружениям, в связи с этим существует необходимость удаления этих загрязнений из сточной воды (табл. 1).

$$
-585-
$$


Таблица 1. Взаимосвязь наличия биополютантов и наносимого вреда на экологическую среду, человека, инженерные сооружения

Table 1. Relationship of bio-pollutant availability and damage for ecological environment, humans and engineering utilities

\begin{tabular}{|c|c|c|}
\hline $\begin{array}{c}\text { Классификационная } \\
\text { принадлежность } \\
\text { микроорганизмов }\end{array}$ & $\begin{array}{c}\text { Наносимый вред экологической } \\
\text { среде и человеку }\end{array}$ & $\begin{array}{c}\text { Наносимый вред } \\
\text { инженерным сооружениям }\end{array}$ \\
\hline $\begin{array}{l}\text { Бактерии: } \\
\text { Zoogloea ramigera } \\
\text { Streptococcus marginatum } \\
\text { Zoogloea filipendula }\end{array}$ & $\begin{array}{l}\text { Вызывает такие заболевания } \\
\text { у человека, как ангина, рожа, } \\
\text { воспаление костного мозга, } \\
\text { сепсис }\end{array}$ & \multirow{2}{*}{$\begin{array}{l}\text { Образуют плотную биопленку, } \\
\text { вызывая уменьшение диаметров } \\
\text { трубопроводов, провоцируют } \\
\text { повышение давления и порывы. } \\
\text { Продукты жизнедеятельности } \\
\text { вызывают коррозийные } \\
\text { изменения инженерных сетей } \\
\text { и оборудования. Подавляют } \\
\text { биологическое окисление в } \\
\text { биореакторах }\end{array}$} \\
\hline $\begin{array}{l}\text { Диатомовые: } \\
\text { Aserionella Formosa } \\
\text { Melozira granulate } \\
\text { Stephanodiscus astraea } \\
\text { Stephanodiscus hantzschii }\end{array}$ & $\begin{array}{l}\text { Заболевания желудочно- } \\
\text { кишечного тракта, кожные } \\
\text { аллергические реакции }\end{array}$ & \\
\hline $\begin{array}{l}\text { Цианобактерии: } \\
\text { Oscillatoria putrida Arthrospira } \\
\text { major } \\
\text { Zygnema stellinum } \\
\text { Anabaena } \\
\text { Aphanizomenon } \\
\text { Microcystis }\end{array}$ & $\begin{array}{l}\text { Токсины этих водорослей } \\
\text { вызывают летальный исход } \\
\text { у рыб, тяжелые отравления } \\
\text { млекопитающих, тяжелые } \\
\text { аллергические реакции у } \\
\text { человека. } \\
\text { Нарушение обмена веществ, } \\
\text { заболевания желудочно- } \\
\text { кишечного тракта, аллергии, } \\
\text { гаффская болезнь, химические } \\
\text { отравления, вызывающие } \\
\text { поражение нервной системы }\end{array}$ & $\begin{array}{l}\text { Водоросли этого рода образуют } \\
\text { налеты на трубопроводах, } \\
\text { оборудовании и сооружениях, } \\
\text { создавая эффект «мокрой } \\
\text { стены», вызывают эффект } \\
\text { вспухания ила, дезактивацию } \\
\text { ила, гибель биоценоза активного } \\
\text { ила }\end{array}$ \\
\hline
\end{tabular}

При анализе схемы водоочистки на предприятиях пищевого комплекса идентичной принадлежности - молочная переработка, выявлена зависимость снижения активности ила в биореакторах от концентрации биополютантов. Так, при содержании 12000-15000 клеток

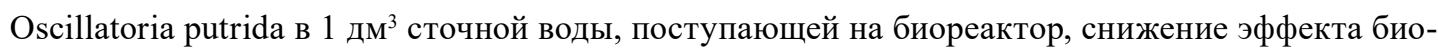
логической очистки наблюдалось на 20 \%. Помимо этого клетки Oscillatoria putrida, объединяясь общей слизистой пленкой, образуют мощные скопления на воздухораспределительных элементах биореактора, снижая, таким образом, кислородонасыщение, вызывая массовую гибель биоценоза активного ила. Более того, цианобактерии выделяют в процессе жизнедеятельности сильнейшие нейротоксические яды, которые невозможно инактивировать при условии кондиционирования сточной воды с применением типовых методов очистки.

В качестве дополнительного узла очистки сточной воды предприятий пищевой промышленности, позволяющего значительно увеличить эффект очистки, предлагается гидротермодинамический реактор лопастного типа с углом раскрытия крыльчатки $45^{\circ}$ с числом вращения ротора 1000-12000 оборотов в минуту.

Данный метод относится к новым разработкам в области водоочистки, кондиционирования сточных вод различного назначения. 
В работах В.М. Ивченко впервые было обращено внимание на комплексное кавитационное воздействие на гомогенные и гетерогенные жидкости, которое возможно использовать в технологических целях. В работах В.М. Ивченко, В.А. Кулагина, А.Ф. Немчина, О.Г. Дубровской, В.В. Евстигнеева и др. показано, что кавитационное воздействие на обрабатываемую среду является одним их эффективных методов интенсификации химико-технологических, гидромеханических и массообменных процессов в жидкостях, деструкции веществ и т.п.

Физико-химические аспекты кавитационных явлений изучены ранее с использованием ультразвуковых генераторов кавитации. Экспериментально установлено, что величина порога, при котором образуется кавитация, зависит от многих факторов, поэтому определение этих значений возможно только для конкретно заданных условий.

В зависимости от внешних факторов схлопывание пузырька может происходить поразному. Особенно сильно это влияние сказывается на последнем этапе схлопывания пузырьков, когда их размеры очень малы. Увеличение плотности и вязкости снижает интенсивность кавитационного воздействия; наличие растворенных и нерастворенных газов в растворе замедляет коллапс пузырьков; силы поверхностного натяжения ускоряют этот процесс.

Образующиеся при схлопывании микроструи обладают высокой скоростью и ударной силой (скорость от 100 до 500 м/с, давление от 1 до 2 тыс. атм). Данные эффекты могут применяться в различных производственных процессах; например, данное свойство кавитации используется для очистки поверхностей от последствий коррозии.

Формы течений для пузырька в жидкости можно условно разделить на четыре типа:

- кавитационную эрозию (подводный взрыв с образованием кумулятивной струи);

- развитие из поверхностного зародыша микропузырька (кипение - кавитация);

- газификацию пограничного слоя (барботаж, аэрация);

- пульсацию парогазового пузырька (гидроакустика, кавитационная технология, водородные камеры).

Некоторые из них поддаются точному математическому описанию в рамках соответствующих моделей сплошных сред.

При резком снижении давления жидкости, даже при малых температурах, всегда имеющиеся в воде микроскопические «ядра» кавитации разрастаются до видимых размеров и образуют белесую среду - жидкость, сплошь заполненную парогазовыми микропузырьками диаметром от 20 до 200 мкм.

О химических процессах, протекающих в водных растворах под воздействием кавитации, известно достаточно много. Внутри схлопывающихся кавитационных микрополостей возникает огромное давление и температура, в таких условиях происходит разложение молекул воды с образованием $\mathrm{H}_{2} \mathrm{O}_{2}$, ОН и $\mathrm{H}$ радикалов, вызывающих различные окислительновосстановительные реакции (рис. 1).

В этих условиях протекают сложные физико-химические процессы, классифицируемые следующим образом:

- окислительно-восстановительные реакции с участием присутствующих в водной среде органических и неорганических веществ;

- цепные реакции в растворе, инициируемые продуктами расщепления присутствующих в растворе примесей; 


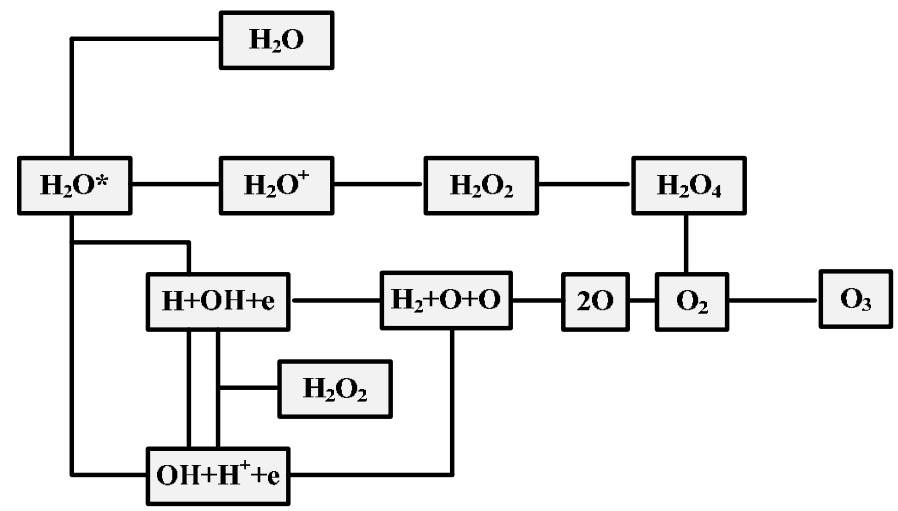

Рис. 1. Схема разложения молекулы воды при кавитационном воздействии

Fig. 1. The scheme of the water molecule decomposition under the action of cavitation

- деструкция макромолекул и инициирование деполимеризации;

- реакции между растворенными газами внутри кавитационных пузырьков;

- дезинтеграция клеток биологических примесей.

Изменение условий проведения технологических процессов также влияет на интенсивность кавитационного воздействия. Так, снижение температуры и давления насыщенных паров повышает интенсивность кавитации, а повышение давления увеличивает скорость кумулятивных струек при схлопывании пузырька. Время кавитационной обработки неоднозначно влияет на конечный результат, не всегда увеличение времени обработки ведет к усилению эффектов и может даже ухудшать конечный результат. Поэтому при кавитационной обработке сточной воды необходимо учитывать не только физические свойства жидкости, но и условия проведения технологического процесса: давление, pH, температуру, солесодержание, длительность обработки, степень турбулентности потоков, наличие твердых частиц, присутствие биологических примесей и т.д.

Пульсационные эффекты кавитации превращают каждый пузырек в кавитанионногидродинамический микрореактор, в котором создаются предпосылки для протекания механохимических реакций. Одновременно происходит и изменение структуры воды с образованием свободных водородных связей, что обуславливает ее повышенную активность и реагентную способность.

Изучение возможности использования кавитации в системах кондиционирования сточных вод проводится многими учеными с использованием различных аппаратов и устройств, генерирующих как акустическую, так и гидродинамическую кавитацию. Имеется достаточно большое количество систематизированных результатов исследования действия ультразвуковой кавитации. Экспериментально исследован механизм химических сдвигов в воде, происходящих под воздействием ультразвуковой кавитации, и сделан вывод о том, что принципиального влияния на проявляющиеся эффекты метод возбуждения кавитации не оказывает, в частности на механотермолиз воды.

Химические процессы, происходящие в воде при гидродинамической и акустической кавитации, одинаковы, но подвергаемый кавитационному воздействию объем воды значи- 
Таблица 2. Эффективность очистки стока технологической схемы после реконструкции

Table 2. Efficiency of treatment of the drain of the technological scheme after reconstruction

\begin{tabular}{|l|c|c|c|c|c|}
\hline \multicolumn{1}{|c|}{ Показатель } & $\begin{array}{c}\text { Исходная } \\
\text { концентрация } \\
\text { мг/л } \\
\text { биологической очистки } \\
\text { с предварительной } \\
\text { флотационной обработкой } \\
\text { мг/л }\end{array}$ & $\begin{array}{c}\text { Концентрация после } \\
\text { биологической очистки } \\
\text { с предварительной } \\
\text { кавитационной обработкой } \\
\text { мг/л }\end{array}$ & $\begin{array}{c}\text { Концентрация после } \\
\text { Взвешенные } \\
\text { вещества }\end{array}$ \\
\hline ХПК & 394 & 36,7 & 50 & 1,03 & 90 \\
\hline БПК & 1550 & 187,3 & 80 & 11,10 & 94 \\
\hline Аммоний-ион & 32,2 & 109,4 & 60 & 6,70 & 94 \\
\hline Фосфат-ион (РО $\left.\mathrm{P}_{4}\right)$ & 25,6 & 21,2 & 20 & 1,06 & 95 \\
\hline Фосфат-ион Р & 7,27 & 0,236 & 20 & 0,003 & 95 \\
\hline АПАВ & 1,47 & 0,1 & 20 & 0,001 & 95 \\
\hline НПАВ & 2,5 & 0,3 & 5,03 & 0,003 & 96 \\
\hline Жиры & 0,29 & 2,3 & 0 & 0,0002 & 96 \\
\hline Биополютанты & 34353066 & 34353066,0 клеток & 0,04 & 96 \\
\hline
\end{tabular}

тельно отличается. При гидродинамическом способе возбуждения кавитации процесс окисления активными частицами возможно реализовать во всём потоке обрабатываемой воды, при акустическом способе зона воздействия ограничивается только вокруг источника генерирования.

Применение данной технологии в системе кондиционирования сточной воды молокоперерабатывающего предприятия в качестве узла интенсификации биореактора позволило добиться высокого качества очистки. Эффективность работы биореактора и всей технологической схемы составляет 98-99 \%, биоценоз ила стабилизировался, концентрация биомассы активного ила достигла 9 г/л (табл. 2).

Применение кавитационных технологий позволяет получить значительный эффект в энерго- и ресурсосбережении за счет снижения экологических нагрузок и формирования оборотных систем водопользования.

Исследование выполнено при финансовой поддержке РФФИ и Правительства Красноярского края в рамках научных проектов №̄№ 17-48-240386, 18-48-242001 и 18-41242004.

\section{Список литературы}

[1] Дубровская О.Г., Евстигнеев В.В., Кулагин В.А. Проблемы биообрастания в оборотных системах замкнутых циклов водопользования и пути их решения, Безопасность жизнедеятельности. 2012, 3, 26-30 [Dubrovskaya O.G., Evstigneev V.V., Kulagin V.A. The problem of biofouling in circulating systems of closed water cycles and their solutions, Bezopasnost' zhiznedeyatel'nost'. 2012, (3), 26-30 (in Russian)]. 
[2] Дубровская О.Г., Евстигнеев В.В., Кулагин В.А. Кондиционирование сточных вод энергетических систем и комплексов, Журнал Сибирского федерального университета, Техника и технологии, 2011, 6(4), 665-675 [Dubrovskaya O.G., Evstigneev V.V., Kulagin V.A. The conditioning wastewater energy systems and complexes, Journal of Siberian Federal University. Engineering \& Technologies, 2011. 6 (4), 665-675 (in Russian)].

[3] Дубровская О.Г. Технология гидротермодинамической обработки природных и сточных вод с использование эффектов кавитащии: дис... канд. техн. наук. Красноярск: Краснояр. гос. техн. ун-т, 2007 [Dubrovskaya O.G. The technology of hydro-thermodynamic treatment of water and wastewater with the use of cavitation effects, Krasnoyarsk: Krasnoyarskii gosudarstvennyi tekhnicheskii universitet, 2007 (in Russian)].

[4] Евстигнеев В.В., Кулагин В.А. Кавитация в технологиях очистки сточных, В мире научных открытий. 2010, 5(11), Ч. 1. 87-90 [Evstigneev V.V., Kulagin V.A. Cavitation in wastewater treatment technology, Mire nauchnykh otkrytii, 2010, 5(11), 87-90 (in Russian)].

[5] Евстигнеев В.В., Кулагин В.А. Гидротермодинамическая технология обработки сточных вод. Вестник Международной академии наук экологии и безопасности жизнедеятельности, 2009, 14(6), 242-245 [Evstigneev V.V., Kulagin V.A. Hydrothermodynamic technology wastewater treatment, Vestnik MANEB, 2009, 14(6), 242-245 (in Russian)]. 